\title{
Second-order fear conditioning as revealed through augmentation of a startle response: Part I'
}

\section{CHRIS ANDERSON, DONALD JOHNSON, ${ }^{2}$ and HOWARD KEMPTON, ${ }^{3}$ University of Notre Dame, Notre Dame, Ind. 46556}

A loud, abrupt auditory startle stimulus was presented 1, 17, and $27 \mathrm{sec}$ following termination of a classically conditioned, fear-evoking, second-order stimulus. Forward, second-order conditioned Ss consistently exceeded the startle magnitudes of backward, second-order conditioned controls at all intervals with one exception (the 1 -sec interval).

With the possible exception of a study by Brogden (1939), early Russian and U.S. attempts to demonstrate second-order classical conditioning incorporated special reinforcement techniques which made difficult the interpretation of their results (Brogden \& Culler, 1935; Eccher \& Culler, 1941; Finch \& Culler, 1934; Pavlov, 1927). Recently, however, less equivocal demonstrations of second-order conditioning have been reported (Anderson, 1967; Anderson, Plant, Johnson, \& Vandever, 1967; Davenport, 1966; Johnson \& Anderson, 1969; McAllister \& McAllister, 1964). The present study analyzed the possible motivational consequences of a second-order fear response. A technique similar to that of Brown, Kalish, \& Farber (1951) was used. They reasoned that any fear-provoking stimulus, as a source of drive, should energize any response tendency that was dominant during or immediately following its presentation. In support of their notion they found that a fear-evoking, first-order conditioned stimulus $\left(\mathrm{CS}_{1}\right)$ could augment the magnitude of an unconditioned startle response. The present experiment primarily was concemed with whether the effects of a second-order, fear-producing stimulus $\left(\mathrm{CS}_{2}\right)$ paralleled those of a $\mathrm{CS}_{1}$ as revealed by Brown et al (1951).

\section{SUBJECTS}

The Ss were 22 male hooded rats which previously had been employed in another study of second-order learning (Anderson et al, 1967, Experiment 2). They were 135-145 days of age at the beginning of experimentation.

\section{APPARATUS}

The chamber in which all first- and second-order conditioning was conducted was constructed of 1/8-in. brass rods which had been molded into circles and mounted flush to the inside surface of three $1 / 4$-in. plastic railings. The chamber was $23 / 4$ in. in diam and 6\%3 in. long, inside, and was housed inside a larger black enclosure which was located in a ventilated refrigerator shell to insure control of extraneous sources of sound and light. The shock was scrambled, and the $\mathrm{CS}_{1}, \mathrm{CS}_{2}$ and US contingencies were controlled by silenced programming equipment. The US ( $135 \mathrm{~V} \mathrm{ac}$ ) was the output of a transformer through a $20 \mathrm{~K}$-ohm, seriesconnected resistor. The $\mathrm{CS}_{1}$ was a $6-\mathrm{V}$ buzzer mounted directly in the middle and to the side of the conditioning chamber. The $\mathrm{CS}_{2}$ was an intermittent $7 \frac{1}{2}-\mathrm{W}$ lamp mounted directly over the center of the conditioning chamber. The $\mathrm{CS}_{2}$ intermittency $(.21 \mathrm{sec}$ on, $.21 \mathrm{sec}$ off) was accomplished by additional silenced timing devices.

The test chamber was a stabilimeter-like device which was housed in a wooden electrically shielded box. The chamber was $6 \frac{1}{2} \times 2 \frac{1}{2} \times 3$ in. high, constructed of Plexiglas, and mounted on a grid floor (1/8 in. in diam stainless-steel rods, spaced $9 / 16$ in. apart and inserted in plastic railings). The grid floor was suspended at each corner by 1/8-in.-diam flexible 6-in. stainless-steel rods, each of which were connected to respective, firmly anchored, aluminum pillars. Centered and connected to one side of the startle chamber was an Astatic No. 2 ceramic phonocartridge. Inserted in place of the stylus was a $21 \%$-in.-long x 1/8-in.diam stainless-steel rod, tapered at one end so that it could be fitted into the stylus receptacle. Abrupt, slight displacements of the startle cage generated voltages due to displacements of this stylus. Voltage output was rectified, filtered, and recorded by an ink-writing millivoltmeter (Model 5C Grass polygraph; 5P1 polygraph preamplifier). Preamplifier sensitivity was set at $.2 \mathrm{mV} / \mathrm{cm}$ for all test sessions except where the magnitude of startle produced pen deflections which exceeded the limit of maximal excursion. The sensitivity then was decreased to either $.5 \mathrm{mV} / \mathrm{cm}$ or $1 \mathrm{mV} / \mathrm{cm}$. Repeated calibration throughout the experiment indicated that the startle transducer produced an approximate linear output for forces ranging from $2.70 \mathrm{~g}$, dropped from a height of 1 in. from the chamber floor level. Test responses, in general, were within this range.

The startle stimulus was the full output of a Grason-Stadler white-noise generator. Duration was $0.2 \mathrm{sec}$. The stimuli were presented through a 5-in. Quam speaker mounted directly to the side and 6 in. from the startle chamber.

\section{PROCEDURE}

The Ss were maintained in separate cages with free access to food and water throughout the entire experiment. All Ss initially were adapted to the startle chamber for a 10-min period on each of two consecutive days. To obtain a baseline startle response, each $S$ was placed in the chamber for a total of $11 \mathrm{~min}$ on each of the next 2 days, the first $5 \mathrm{~min}$ of which went uninterrupted. The startle stimulus then was presented five times. The average interstartle interval was $1 \mathrm{~min}$, and magnitude of startle was recorded.

Since approximately 40 days and nine extinction test trials had elapsed since they previously were conditioned, all Ss then were reconditioned. (Prior conditioning had involved 20 first- and 25 second-order trials. A forward-conditioning contingency had been employed on all trials for the experimental group while the controls were treated identically save for a backward contingency for second-order trials only.) In the present experiment a total of 7 first-order trials were semirandomly interspersed with 13 second-order conditioning trials. First-order trials were identical for the two groups, and involved a 5 -sec presentation of the buzzer $\left(\mathrm{CS}_{1}\right)$ which overlapped and co-terminated with the 2 -sec US. For the experimental group $\left(\mathrm{FC}_{\mathrm{FC}}\right)$ secondorder trials consisted of a 10-sec presentation of the intermittent light $\left(\mathrm{CS}_{2}\right)$ which overlapped and co-terminated with the $5-\mathrm{sec}$ $\mathrm{CS}_{1}$. For controls $\left(\mathrm{FC}_{\mathrm{BC}}\right)$, the of fset of the $\mathrm{CS}_{1}$ was followed by $\mathrm{CS}_{2}$ onset 10 seclater. Intertrial interval averaged $60 \mathrm{sec}( \pm 15 \mathrm{sec})$.

The Ss were returned to the startle chamber $24 \mathrm{~h}$ later, and, following a 5-min adaptation period, were presented the startle stimulus three times at $1-\mathrm{min}$ intervals to assess possible baseline changes following conditioning. Three additional startle stimuli were presented 1 sec following termination of the 10-sec $\mathrm{CS}_{2}$. The inter $\mathrm{CS}_{2}$ interval averaged $3 \mathrm{~min}$. Three additional test trials were given following 5-min habituation periods on each of the next 2 days. The only differences between the first and next 2 days was that no startle-adaptation trials were given, and the $\mathrm{CS}_{2}$-startle stimulus interval was $17 \mathrm{sec}$ on Day 2 and $27 \sec$ on Day 3.

\section{RESULTS}

The criterion for a response was any pen deflection which exceeded the baseline by $1 \mathrm{~mm}$ or more within a $1 / 2-\mathrm{sec}$ period from onset of the startle stimulus. Because of the skewed distributions, each response was 


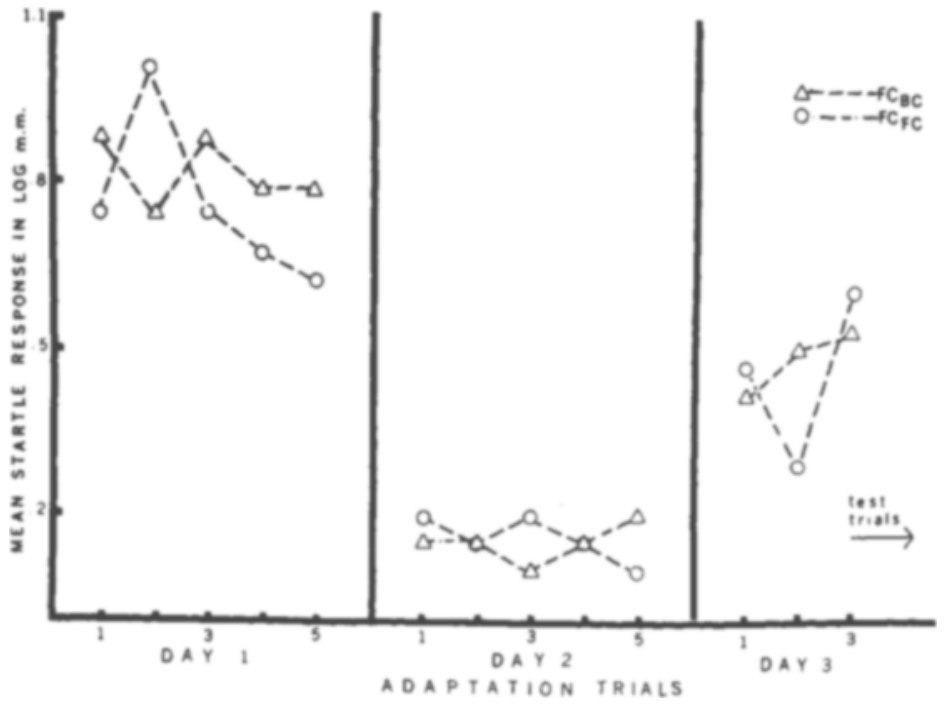

converted to its logarithm before the data were treated statistically.

Figure 1 summarizes the mean log startle responses for both groups on the startlehabituation trials preceding conditioning (Days 1 and 2) and on the three adaptation trials following conditioning and immediately preceding testing. A three-way ANOVA indicated a near-significant Trials by Days interaction and a reliable days effect $(p<.01)$ thus supporting the observation of a decrease in startle magnitude over the three trials of Day 1 but not on Day 2, as well as a pronounced habituation of the startle response for all of Day 2. No other effects were reliable. Marked recovery of startle magnitude for both groups was observed on the three postconditioning, startle-adaptation trials.

Figure 2 summarizes the results obtained on the test trials. With the exception of Test Day 1 the differences in $\mathrm{CS}_{2}$-produced startle magnitudes were statistically reliable The forward, second-order conditioned group $\left(\mathrm{FC}_{\mathrm{FC}}\right)$ evinced startle magnitudes which clearly exceeded those of the backward, second-order conditioned controls. A three-way ANOVA produced a significant $F$ for the groups $(F=7.38$, $\mathrm{df}=1 / 20, \quad \mathrm{p}<.025)$, days $(\mathrm{F}=13.43$, $\mathrm{df}=1 / 20, p<.01$ ), and the Groups by Days interaction $(F=19.10, \mathrm{df}=1 / 20, \mathrm{p}<.01)$ effects. No other effects achieved significance. A grand means analy sis (Winer, 1962, p. 56) was performed for Test Days 1 $(F<1), 2(F=11.98, d f=1 / 20, p<.01)$ and $3(F=11.37, d f=1 / 20, p<.01)$, and indicated that the Groups by Days interaction could be accounted for by the lack of differences in startle magnitudes on Test Day 1.

\section{DISCUSSION}

These data indicated that a second-order, fear-conditioned stimulus can produce

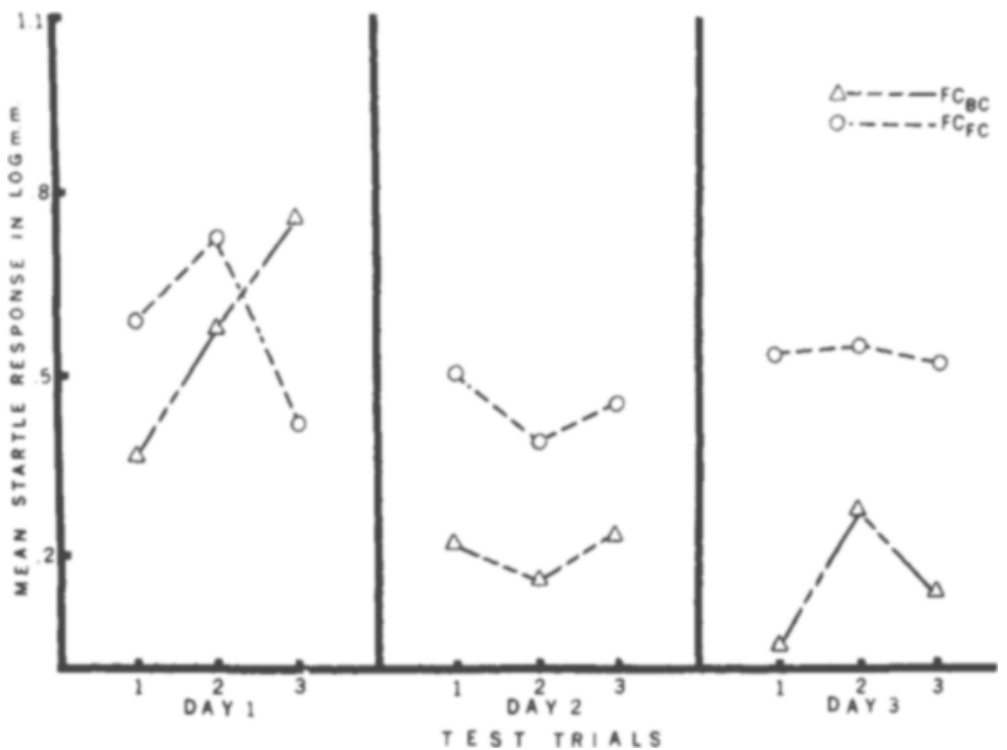

Fig. 1. Mean startle magnitudes ( $\log \mathrm{mm}$ ) for experimental $\left(\mathrm{FC}_{\mathrm{FC}}\right)$ and control $\left(F C_{B C}\right)$ groups on startle-adaptation trials prior to (Days 1 and 2) and following (Day 3) conditioning.

facilitation of a startle response. However, the $\mathrm{CS}_{2}$-produced startle magnitudes of the forward, second-order conditioned Ss never exceeded those produced by the startle stimulus immediately preceding testing. Apparently, some generalized or residual effect of the reconditioning procedure uniformly altered the preconditioning startle baseline response levels for both groups. It thus would appear that the test performance of the control Ss $\left(\mathrm{FC}_{\mathrm{BC}}\right)$ involved a return to the preconditioning baseline levels, and that the larger startle responses of the experimental Ss on Test Days 2 and 3 represented "true" augmentation rather than perpetuation of the altered baseline which occurred immediately preceding testing. However, this latter interpretation is confounded by the fact that the $\mathrm{CS}_{2}$-startle stimulus interval was $1 \mathrm{sec}$ on Test Day 1 and 17 and $27 \mathrm{sec}$, respectively, on Test Days 2 and 3. Thus, conditioningproduced residual activation may have been confounded with the $\mathrm{CS}_{2}$-startle stimulus interval, as well as with possible extinction of the effect of the $\mathrm{CS}_{2}$ over days. Moreover, it also could be asserted that the startle-habituation procedure, which preceded testing only on Test Day 1 , might have served to "mask" the observed effect had it preceded the other test days. Another experiment thus was felt necessary to evaluate these possible objections.

It may be noted that another objection might be raised because a control for the possible innate aversiveness of the $\mathrm{CS}_{1}$ was not included. That is, the $\mathrm{CS}_{1}$ conceivably could have served as a US-like stimulus even in the absence of pairings with shock. However, it previously was found that a control for this possibility was unnecessary for the general procedure we have used (cf. Anderson et al, 1967; Anderson, Plant, \& Paden, 1967), that the available data on the aversive properties of buzzers was equivocal (Myers, 1965; Smith, McFarland, \& Taylor, 1961), and that the typical result of repeated buzzer presentations was habituation or adaptation. The latter observation probably accounts for the fact that there seems to be no successful reports of classical learning when a buzzer has been the US.

Fig. 2. Mean log startle response magnitudes for each group following of fset of the $\mathrm{CS}_{2}$. The $\mathrm{CS}_{2}$-startle stimulus interval was $1 \mathrm{sec}$ on Day 1, $17 \mathrm{sec}$ on Day 2, and $27 \mathrm{sec}$ on Day 3. 


\section{REFERENCES}

ANDERSON, D. C. Higher-order conditioning in the infrahuman organism: Implications for response analysis, motivation theory, and a human model. Journal of Utah Academy of Letters, Arts and Sciences, 1968.

ANDERSON, D. C. PLANT, C., JOHNSON, D., \& VANDEVER, J. Second-order aversive classical conditioning. Canadian Journal of Psychology, $1967,21,120131$.

ANDERSON, D. C., PLANT, C., \& PADEN, P. Conditioned suppression of a running response as related to competing responses, drive, and basal skin resistance level. Joumal of Comparative \& Physiological Psychology, 1967, 63, 282-287.

BROGDEN, W. J. Higher-order conditioning. American Joumal of Psychology, 1939, 52 579-591.

BROGDEN, W. J., \& CULLER, E. Experimental extinction of higher-order responses. American Journal of Psychology, 1935, 47, 663-669.

BROWN, J. S., KALISH, H. I., \& FARBER, I. E. Conditioned fear as revealed by magnitude of startle response to an auditory stimulus. Joumal of Experimental Psychology, 1951, 41, 317-328.

DAVENPORT, J. W. Higher-order conditioning of fear. Psy chonomic Science, 1966, 4, 27-28.

ECCHER, W., \& CULLER, E. Reciprocal facilitation of the conditioned and conditioning mechanisms. Joumal of Comparative Psychology, 1941, 31, 223-231.
FINCH, G., \& CULLER, E. Higher-order conditioning with constant motivation. American Journal of Psychology, 1934, 46, 596-602.

JOHNSON, D. E., \& ANDERSON, D. C. Acquisition of a second-order classically conditioned response. Canadian Journal of Psychology, in press.

MCALLISTER, D. E., \& McALLISTER, W. R. Second-order conditioning of fear. Psychonomic Science, $1964,1,383-384$.

MYERS, A. K. Instrumental escape conditioning to a low-intensity noise by rats. Joumal of Comparative \& Physiological Psychology, 1965, 60, 82-87.

PAVLOV, I. P. Conditioned reflexes. Trans. by G. V. Anrep. London: Oxford University Press, 1927

SMITH, O. A., McFARLAND, W. L., \& TAYLOR, E. Performance in a shock-avoidance conditioning situation interpreted as pseudoconditioning. Journal of Comparative \& Physiological Psychology, 1961, 54, 154-157.

\section{NOTES}

1. This research was supported, in part, by Grants $\mathrm{MH} 12135-02$, MH 14436-01, and MH 15364-01 from the National Institutes of Health, USPHS. These data were reported at the Rocky Mountain Psychological Association, Salt Lake City, 1967

2. Now at the University of Minnesota.

3. Now at Brigham Young University.
CS-produced augmentation of startle when the US had been delivered through the back rather than the paws of their Ss during conditioning.

Importantly, these authors neglected the possibility that a back-shock also may have produced unique postural changes, but which could have been antagonistic to the typical startle reaction evinced by the startle stimulus. The CS, as a source of drive, still could have augmented any reaction which had a high probability of occurrence in its presence. Since the back-shock-produced conditioned posture may have been associated with the CS, such would simply have introduced the element of response competition into the startle-augmentation procedure. Interestingly, a more direct test of the postural vs drive-augmentation hypotheses would simply be to tally and analyze the number of movements during the interval between CS termination and presentation of the startle stimulus. No movements during this CS-startle stimulus interval would reflect maintenance of a CS-produced postural adjustment. If movement occurred, such would suggest disruption of the presumed postural adjustment. Further, in order to retain a postural-adjustment hypothesis, the number of movements during the CS-startle interval should be negatively correlated with the magnitude of jump, and that control Ss should move with less vigor. Thus, the present investigation both attempted to unconfound certain features of the study of Anderson et al (1969) and to evaluate the postural vs driveaugmentation hypothesis using the strategy outlined above.

\section{SUBJECTS}

The Ss were 32 male albino rats, randomly selected from the experimental and control groups of another study (Johnson \& Anderson, 1969). Age and prior experimental experiences at the beginning of this study approximated those of the Ss of Anderson et al (1969).

\section{APPARATUS}

The apparatus was that of Anderson et al (1969). tions in motivation level as postulated by Brown, Kalish, \& Farber (1951). Kurtz \& Siegal (1966) proposed that foot-shock produces postural changes which can become associated with the $\mathrm{CS}$, and that these postural changes are uniquely sympathetic with the startle response. Hence, presentation of the featevoking $C S$ in concert with an auditory startle stimulus could produce an augmented startle reaction because of some presumed additive combination of CS-produced postural changes to the startle reaction per se. These authors concluded support for their position because they failed to obtain

\section{PROCEDURE}

The procedure was similar to that of Anderson et al (1969). Adaptation to the stabilimeter chamber involved 3 , rather than 2 , days of presentation of the startle stimulus in an otherwise identical preconditioning adaptation procedure. Conditioning treatment was exactly the same as for the Ss of Anderson et al (1969). The test procedure was altered in the following manner.

Twenty-four hours following conditioning, the Ss were administered five additional startle stimuli (1-min average interstimulus interval) to determine whether 